\title{
La prensa en el proceso emancipador de la América española: Información, propaganda y formación
}

\author{
Marta GONZÁlez SAN RUPERTO \\ Universidad Complutense de Madrid \\ marta.gonzalez@ccinf.ucm.es
}

Recibido: $18 / 04 / 2011$

Aceptado: 25/05/2011

\begin{abstract}
Resumen
La invasión de la Península por parte de Napoleón supuso en España el inicio de la Guerra de Independencia y en las colonias americanas el arranque de los procesos emancipadores. Inicialmente, en América encontramos dos tendencias, realistas y patriotas, que comparten la lealtad al monarca español pero discrepan sobre la forma de ejercer el poder. El enfrentamiento entre estas dos corrientes dará lugar a las guerras de independencia. En estos conflictos ambos bandos recurrirán a la prensa para dar a conocer sus ideas, rechazar las del oponente y formar a los ciudadanos. Pese al escaso número de imprentas disponibles y al ínfimo porcentaje de la población que sabía leer, el interés de unos y otros por poner en marcha sus propias publicaciones revela la creciente importancia de la palaba escrita como arma de guerra.

Palabras clave: América; prensa; propaganda; prensa emancipadora; prensa realista; Guerras de Independencia.
\end{abstract}

\section{The press in the process of emancipation of Spanish America: Information, propaganda and training}

\begin{abstract}
The invasion of the Iberian Peninsula by Napoleon marked the beginning of the Independence War in Spain and the starting of the emancipation processes in the American colonies. There were two groups, royalist and patriots, who share loyalty to the Spanish king but disagree on how to exercise power. The clash between these trends will lead to the independence wars. In those conflicts, both sides used the press to show their ideas, criticize their opponents and educate citizens. Despite the small number of available printers and the small percentage of population that could read, the interest of all of them to start their own publications shows the growing importance of words as war weapons.
\end{abstract}

Key words: America; press; propaganda; insurgent press; royalist press; Independence Wars.

\section{Referencia normalizada}

González San Ruperto, M. (2011). La prensa en el proceso emancipador de la América española: Información, propaganda y formación. Historia y Comunicación Social, Vol. 16, páginas 51-67.

Sumario: 1. Introducción; 2. El Origen: El periodismo ilustrado; 3. La prensa durante el proceso emancipador; 3.1. Prensa patriota o emancipadora; 3.2. Prensa realista; 4. Conclusiones; Referencias bibliográficas. Notas

\section{Introducción}

En el año 1810 comenzó el proceso emancipador de la América española. Fue un proceso rápido y complejo, que puede estudiarse desde diferentes perspectivas. En 
el marco de este monográfico dedicado al bicentenario de la independencia de las antiguas colonias españolas y portuguesas en América, el propósito de este trabajo es conocer algo más de esta compleja época a través de los testimonios que nos dejó la prensa.

Aunque aún en sus primeras fases de desarrollo, marcadas por la falta de imprentas y la escasez del público lector, estas publicaciones precarias desempeñaron un papel muchas veces poco conocido en el proceso emancipador como herramienta de información y de formación y, por supuesto, de adoctrinamiento y propaganda.

Partiendo de este presupuesto, en este artículo se trata de analizar la evolución de las principales publicaciones de la América española, desde los primeros escritos de carácter ilustrado que, sin vocación soberanista, contribuyeron a ir creando una cierta conciencia nacional, hasta las publicaciones más combativas que quisieron acercar al público a los grandes debates de la época e incluso conseguir su apoyo a la lucha armada.

Existen diversos manuales y monografías sobre la historia de la prensa en Iberoamérica, en los que podemos encontrar referencias a las publicaciones de la época. Sin embargo, en la mayoría de las ocasiones hallamos gran cantidad de títulos pero poca información sobre los contenidos. También encontramos publicaciones más específicas, centradas normalmente en un solo país, pero falta una visión de conjunto.

Además de la consulta de la bibliografía disponible, la metodología seguida para esta investigación ha consistido en el análisis de las principales publicaciones conservadas y que, afortunadamente, han sido digitalizadas en diversos países, así como de la documentación recopilada por la autora en sus años de docencia de la asignatura Historia del Periodismo Iberoamericano. Así, se ha analizado la evolución de la prensa de esos años, con especial atención a aquellas publicaciones más significativas por su influencia o duración. Por lógicas razones de tiempo y espacio disponible, el artículo se centra fundamentalmente en la gran publicación patriota mexicana El Despertador Americano y en las dos principales publicaciones nacidas para contrarrestarla: El Anti-Hidalgo y Diálogos entre Filopatro, Acerario y Moros.

\section{El origen: El Periodismo Ilustrado}

En el último cuarto del siglo XVIII fue desarrollándose en América una prensa de carácter ilustrado. Estas publicaciones no tenían afán emancipador sino que su objetivo era formar, educar y, en definitiva, extender entre la sociedad americana los nuevos conocimientos que se estaban desarrollando en Europa. Por tanto, estos impresos van a centrarse en materias relacionadas con la ciencia, la economía, la literatura, la flora y la fauna.

Las gacetas literarias y los mercurios fueron el vehículo ideal del pensamiento ilustrado para llegar a los estratos privilegiados de las colonias. Estaban muy influenciadas por los periódicos y libros, incluso obras prohibidas, que llegaban en barco desde Europa. 
En el Virreinato de Nueva España, el primer territorio americano que contó con imprenta, encontramos el primer ejemplo de este tipo de publicación, el Diario Literario de México, fundado por José Antonio Alzate en 1768, que acompañaba su título con una clara declaración de intenciones "dispuesto para la utilidad pública a quien la dedica" . Por problemas con las autoridades se publicó durante tres meses en los que se centró en informaciones y consejos útiles sobre ciencia, agricultura, astronomía y minería.

Alzate, sacerdote criollo ilustrado, naturalista, historiador y astrónomo, trató de educar a sus conciudadanos y dejar constancia de sus trabajos científicos a través de diversas publicaciones: Asuntos varios sobre Ciencias y Artes (1772) y Observaciones sobre Física, Historia Natural y Artes Útiles (1787), que posteriormente pasó a denominarse $L a$

Nüm. 16. Miércoles 10. de Febrero de 1773. MERCURIO VOLANTE, Dedicado al Excelentivitio Senor FREI DON ANTONIO MARIA BUCARELI I URSUA, VIRREI DE EGTA NugVa España, \&C. EC.

Pir D. Irsoof Ignacios Rartislacha, Dictor an Madicina.

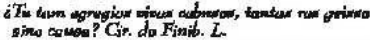

CONTINUACION DE LA MEMORLA SOBRE la impurtancia da la Anatemía.

ns

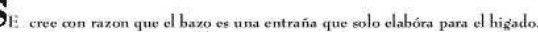

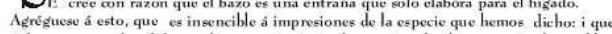
Agrégucse á esto, que es insencible á impresiones de la especie que hemos dicho: i que
si fuese comprexhendido en el acrecentamiento de su natural volumen, sería observable si fuese compreshendido en el acrecentamiento de su natural volumen, seria observa



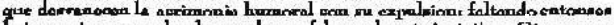

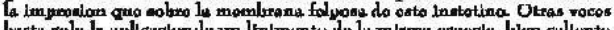

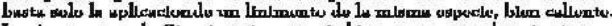

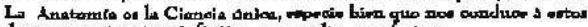

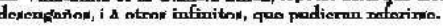

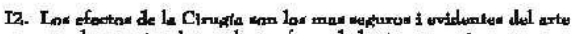

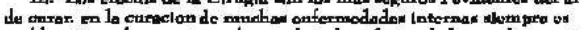



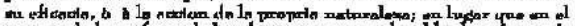



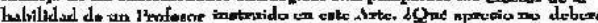
hecorso dio tin Penfotse en Cirugliu, yau nouno

Gaceta de la Literatura y se publicó hasta 1795.

También en Nueva España podemos destacar el Mercurio Volante, obra del médico y matemático mexicano José Ignacio Bartolache. En sus 16 números, que vieron la luz entre 1772 y 1773 , Bartolache buscó difundir, según afirmaba la leyenda de todos los ejemplares, "noticias importantes y curiosas sobre varios asuntos de física y medicina". La publicación estaba dedicada al virrey Antonio María de Bucareli y, según explicaba su autor en el primer número, que "ninguno espere nada de política ni de lo que tocare, aunque fuese de un modo muy indirecto al gobierno"2.

En el virreinato del Perú, la publicación ilustrada más destacada fue el

Mercurio Peruano de Historia, Literatura y Noticias Públicas, editada por Jacinto Calero e impresa por Bernardino Ruiz en Lima. Publicada semanalmente entre 1791 y 1795 se convirtió, según el profesor Enrique Ríos, en el órgano de expresión "de la élite intelectual y profesional limeña". Destaca que "no ha sido probado" que la Sociedad Académica de Amantes del País aportara fondos económicos a su publicación, como sostienen otros autores, "sino más bien confianza y protección moral" (1994: 104).

En el Mercurio Peruano colaboraron diversos escritores que posteriormente adquirieron una enorme relevancia en la era de la independencia, como el médico y político José Hipólito Unanue, posterior ministro de Hacienda y presidente del Consejo de Ministros. 
El Mercurio se vio obligado a cerrar cuando el virrey Gil de Taboada le retiró la subvención que había permitido su puesta en marcha, probablemente alarmado por algunos de sus escritos que, si bien no defendían abiertamente ideas emancipadoras, estaban contribuyendo a crear una idea de patria en Perú, diferente a la defendida por las autoridades coloniales.

En el Virreinato del Río de la Plata también encontramos varios ejemplos relevantes de este tipo de prensa. En Buenos Aires apareció en 1801 El Telégrafo Mercantil, Rural, Político, Económico e Histórico del Río de la Plata, dirigido por Francisco Cabello y Mesa ${ }^{3}$. Con objetivos claramente ilustrados, fue el primer periódico del Virreinato del Plata y el que extendió el uso del adjetivo "argentino" para referirse a todo lo relacionado con la zona del Río de la Plata y la ciudad de Buenos Aires. Contó entre sus colaboradores con intelectuales como Pedro Cerviño y personajes de gran importancia en el proceso emancipador como Manuel Belgrano o Juan José Castelli.

El Telégrafo Mercantil publicó 100 números, además de varios suplementos y extraordinarios, entre 1801 y 1802, cuando fue definitivamente clausurado por las autoridades tras haber recibido varias advertencias por sus críticas más o menos veladas a las políticas virreinales.

La labor del Telégrafo Mercantil fue continuada en Montevideo por Juan Hipólito Vieytes, quien publicó el Semanario de Agricultura, Industria y Comercio entre 1802 y 1807 . Esta publicación se centró en cuestiones económicas, fundamentalmente en la modernización de la agricultura, pero también trató otros temas novedosos como la situación de la población indígena o la educación femenina. Entre sus colaboradores más destacados encontramos a Manuel Belgrano.

Pese a que no se trataban de publicaciones políticas, algunas de ellas tuvieron problemas con las autoridades ya que el control tanto del poder civil como del eclesiástico era férreo. Sin embargo, las publicaciones ilustradas contribuyeron a ir sentando las bases de una cierta conciencia nacional y pusieron los cimientos de lo que algunos años después sería la prensa emancipadora.

\section{La prensa durante el proceso emancipador}

Tras la invasión napoleónica de España, la mayoría de la población de la América española mostró su rechazo a los franceses y su apoyo a la monarquía hispana. Sin embargo, pronto surgieron dos tendencias políticas contrapuestas:

* Una, llamada realista, que estaba compuesta mayoritariamente por altos funcionarios de la Corona, que rechazaban cualquier aspiración independentista y que preferían mantener la obediencia al Consejo de Regencia y aguardar, al mismo tiempo, el desenlace de los acontecimientos políticos en España.

* Otra, conocida como patriota, que estaba representada fundamentalmente por miembros de las élites criollas locales, que postulaba la creación de Juntas de Gobierno propias para los territorios americanos. 
En un principio el grupo patriota no reclamaba la separación de España, sino que buscaba defender los derechos del rey Fernando al trono y prepararse de cara a una posible invasión francesa en tierras americanas. Sin embargo, su pretensión de crear Juntas de Gobierno autónomas ya apuntaba a que querían asumir el protagonismo en el gobierno apartando de sus cargos a las autoridades españolas, a las que acusaban de corruptas y poco eficaces.

Ambos bandos contaron con sus órganos de prensa, a través de los cuales trataron de informar del desarrollo de la situación, difundir sus ideas, denigrar a sus oponentes y formar políticamente a sus conciudadanos.

Las publicaciones de estos primeros momentos, muy controladas por el poder colonial, se sumaron a la lucha que tenía lugar en la Península con informaciones acerca de las victorias españolas sobre las tropas galas, proclamas de adhesión a la resistencia e incluso la publicación de los donativos que los ciudadanos de las colonias realizaban para sostener el esfuerzo bélico.

Evidentemente, no se puede exagerar la importancia de estas publicaciones, ya que fueron de vida efímera y de cortas tiradas. Sin embargo, y pese a los elevadísimos índices de analfabetismo de la época, alcanzaron una cierta difusión, especialmente las publicaciones emancipadoras o patriotas, que solían ser leídas en voz alta y ampliamente discutidas en todo tipo de reuniones.

Al problema de la escasa circulación de estos impresos, hay que añadir las dificultades de la población criolla para acceder a la imprenta, cuyo uso estaba controlado por las autoridades, por lo que muchos de estos escritos, especialmente en la fase inicial del proceso emancipador, circularon en forma de manuscritos y, la mayor parte de las veces, de forma clandestina.

Para dar a conocer sus ideas, los grupos criollos tuvieron que romper con la represiva normativa existente, posteriormente recogida en la Novísima recopilación de las Leyes de España, que exigía contar con licencia de la autoridad correspondiente (juez de imprentas o Consejo de Indias, fundamentalmente) para poder publicar periódicos, libros o folletos. Así, se establecía que el "examen y licencias para imprimir los papeles periódicos, que no pasen de cuatro o seis pliegos impresos, corra a cargo del juez de imprentas" 4 . En cuanto a las prohibiciones, se fija la "prohibición de introducir, vender ni tener libro alguno de los prohibidos por el Santo Oficio de la Inquisición", así como la "prohibición de papeles sediciosos y contrarios a la fidelidad y tranquilidad pública"s.

A partir de 1808 empezaron a circular muchos panfletos y pasquines manuscritos, la mayor parte de las veces de carácter anónimo. Como explica Patricio Bernedo (2004: 138):

"En ellos se fue tomando posición respecto a la actitud que debía adoptarse ante la ausencia del rey, y respecto de los derechos que tenían los americanos en este contexto a formar Juntas de Gobierno, a la igualdad de representación en las instancias centrales de gobierno en España y a la libertad que tenían para expresar soberanamente sus opiniones". 
Entre los manuscritos de carácter más culto podemos destacar los de Melchor de Talamantes, un fraile mercedario nacido en Lima que tuvo un destacado papel en la Junta de Gobierno de México, donde se difundieron sus principales escritos (Representación nacional de las colonias, Discurso filosófico y El Plan de Independencia). En ellos defendía que la "representación nacional, la libertad e inde-

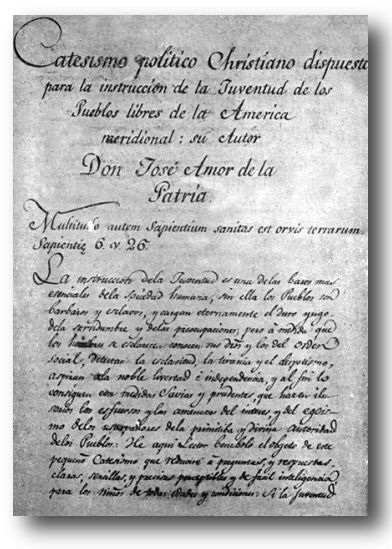
pendencia de cualquier otra nación son cosas casi idénticas" 6 . Fue juzgado y encarcelado en una prisión de la Inquisición, donde murió.

En esta línea, podemos señalar también el Catecismo Político Cristiano, escrito con el pseudónimo de Don José Amor de la Patria, que circuló en Chile y Perú:

"Hemos sido colonos y nuestras provincias han sido colonias y factorías miserables. Se ha dicho que no; pero esta infame cualidad no se borra con bellas palabras, sino con la igualdad perfecta de privilegios, derechos y prerrogativas. Por un procedimiento malvado y de eterna injusticia, el mando, la autoridad, los honores y las rentas han sido el patrimonio de los europeos/españoles"7.

Con afirmaciones como éstas y temiendo las posibles represalias de las autoridades coloniales no es de extrañar que su autor optara por el anonimato, aunque con frecuencia se apunta a la posible autoría de Camilo Henríquez, posterior responsable del periódico emancipador La Aurora.

También encontramos numerosos pasquines, especialmente cuando se han iniciado las revueltas, de carácter muchas veces vulgar, que no invitan a la reflexión política sino que buscan animar a la lucha o amedrentar al enemigo, como éste mexicano, recogido por François Xavier Guerra (2002:137):

"Europeos contumaces. Las armas americanas preponderantes en su partido, os anuncian una ruina total, la de vuestros intereses y la de vuestras familias, sino hacéis algunos esfuerzos visibles que acrediten la benevolencia con que os adirais [sic] a nuestro partido".

A partir de abril 1810, tras la formación de Juntas de Gobierno en las principales ciudades americanas, la situación en América tomó otro camino, que buscaba otorgar legitimidad a las nuevas autoridades locales. Fue entonces cuando las Juntas de Gobierno americanas, y los grupos que las apoyaban, dieron un fuerte impulso a la instalación de imprentas, que hasta entonces habían sido escasas, en sus respectivos países. La mayor disponibilidad de imprentas en las principales ciudades americanas posibilitó la aparición de nuevas publicaciones de periodicidad y duración variable. Este fenómeno también se vio favorecido por la aprobación de la libertad de imprenta por las Cortes de Cádiz en 1810, que sirvió de modelo para que en distintos territorios de la América española se aprobaran leyes similares. 
Con estas publicaciones, impulsadas por los criollos desde la oposición a la metrópoli o ya desde el recién conquistado poder político, lo que se pretendía era criticar a las autoridades coloniales, otorgar legitimidad a las nuevas autoridades y uniformar a la opinión pública en torno a los principios del nuevo gobierno. En estos impresos encontramos normalmente decretos, proclamas y manifiestos. Así como relatos de los sucesos y batallas relacionados con la guerra tanto en Europa como en América.

La prensa se convertirá rápidamente en uno de los principales medios de propaganda de las ideas emancipadoras. En el periodo de 1810 a 1825 aparecieron muchos periódicos, algunos como veremos posteriormente eran oficialistas (la prensa realista), pero la mayor parte eran prensa doctrinal, que en un primer momento sirvió como vehículo expresión de las ideas emancipadoras y que, una vez lograda la autonomía, contribuirían a la construcción del nuevo orden político.

\subsection{Prensa patriótica o emancipadora}

Quizá la primera publicación que podemos considerar emancipadora fue $\mathrm{El}$ Correo del Comercio de Manuel Belgrano, uno de los líderes de la milicia criolla en el Virreinato del Río de la Plata y figura destacada de la independencia Argentina. Con esta publicación Belgrano, que contó con la colaboración de Vieytes, se proponía impulsar la agricultura, la industria y, sobre todo, la educación. Además, dedicaba un espacio destacado a las actividades comerciales de Buenos Aires y Montevideo.

En cuanto a la educación, insistía en la necesidad de inspeccionar el nivel de las escuelas, cuyo abandono denunciaba, y recomendaba la puesta en marcha de escuelas gratuitas en el campo. Además, defendía el derecho a la educación de las mujeres ya que consideraba que, "por desgracia, el sexo que principalmente debe

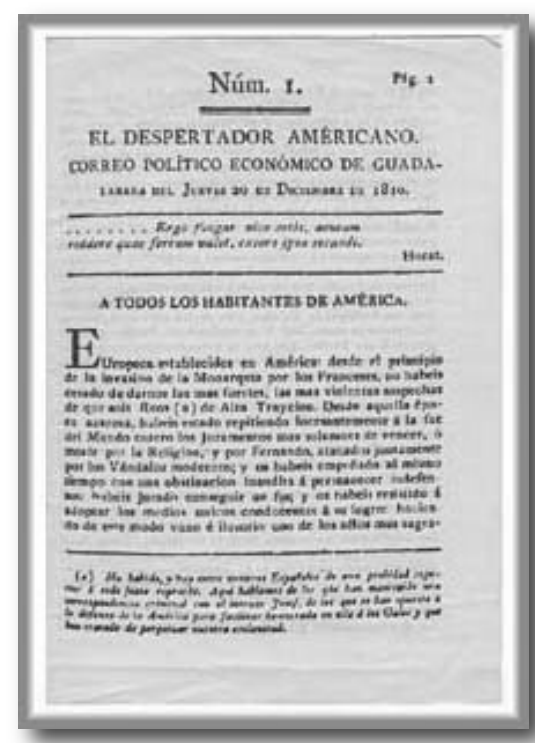
estar dedicado a sembrar las primeras semillas lo tenemos condenado al imperio de las bagatelas y de la ignorancia"8.

El Correo del Comercio continuaba con la línea del periodismo ilustrado, sin embargo, los acontecimientos revolucionarios en Buenos Aires provocaron un giro en la publicación, que se politizó mucho hasta su clausura en abril de 1811.

Sin embargo, el gran ejemplo de publicación patriota aparecerá unos meses después en México: El Despertador Americano. Pese a que sólo se editaron siete números, entre el 20 de diciembre de 1810 y el 17 de enero de 1811 , y su tirada no superaba los 2.000 ejemplares, la publicación impulsada por Miguel Hidalgo tuvo una notable repercusión.

La lucha por la independencia arrancó en México el 16 de septiembre de 1810 con el 
famoso 'Grito de Dolores' cuando Hidalgo, cura de Dolores, al frente de un grupo de mestizos, indios y criollos, tomó Guanajuato. Posteriormente, se refugió en Guadalajara donde organizó un gobierno insurgente y, entre otras medidas, abolió la esclavitud. El temor de la aristocracia criolla ante las reivindicaciones de los sectores más desfavorecidos del virreinato hizo que se aliara con los españoles. La rebelión fracasó e Hidalgo fue capturado y ejecutado en 1811.

Hidalgo había dado a conocer sus principales ideas en doce proposiciones que circularon el 10 de octubre. El también sacerdote Francisco Severo Maldonado viajó a Guadalajara para proponer a Hidalgo la puesta en marcha de una publicación que recogiera sus ideas y animara a la lucha. De esta forma, el 20 de diciembre salió el primer número de El Despertador Americano, subtitulado "Correo Político Económico de Guadalajara", que más que un periódico parecía una proclama, dirigida "a todos los habitantes de América", en la que denunciaba la apatía de los españoles instalados en América ante la invasión francesa de la Península y su posible complicidad con los galos:

“iEuropeos establecidos en América! desde el principio de la invasión de la Monarquía por los Franceses, no habéis cesado de darnos las más fuertes, las más violentas sospechas de que sois Reos de alta traición. Desde aquella época azarosa, habéis estado repitiendo incesantemente a la faz del Mundo entero los juramentos más solemnes de vencer, o morir por la Religión, y por Fernando, atacados juntamente por los Vándalos modernos; y os habéis empeñado al mismo tiempo con una obstinación inaudita a permanecer indefensos: habéis jurado conseguir un fin; y os habéis resistido a adoptar los medios únicos conducentes a su logro"9.

Defiende que los americanos, en defensa de su fe y su rey, amenazados por Napoleón, deben levantarse también en armas contra la invasión francesa "ino debimos los Americanos, en desempeño de la fe jurada, tomar luego una actitud guerrera, y ponernos en un respetable estado de defensa?" y denuncia el empeño de los peninsulares en impedir que los americanos tomen las armas:

“¿Por qué habéis querido privarnos a nosotros esta defensa, a nosotros más aptos para ello como al fin endurecidos en la adversidad y los trabajos? ¿Por qué habéis querido hacernos cómplices de vuestros execrables perjurios? ¿Por ventura la Religión Cristiana no prescribe unas mismas obligaciones y deberes al Europeo, que al Americano? ¿Sólo el Gachupín estará obligado a derramar su sangre por su Fe, y no lo estará el Criollo igualmente? ¿O los franceses sólo serán enemigos de la Religión en España, y protectores de sus Dogmas en el Imperio Mexicano? ${ }^{10}$

En el segundo número de El Despertador Americano ya se habla abiertamente de independencia "nos creemos autorizados por el Ser Supremo, de quien recibimos los mismos derechos naturales que los demás hombres, para aspirar abiertamente a la independencia" 11

El tercer número comienza afirmando que el despertador "va haciendo efecto" y que ya se oye hablar a algunos "de los que poco antes estaban durmiendo". Tras dar 
cuenta de una victoria de los insurgentes en Sonora, concluye con un “ $i V i v a$ la religión! ¡Viva la independencia!"12

Desde las páginas de El Despertador, Hidalgo, sacerdote ilustrado buen conocedor de las teorías de Rousseau y los enciclopedistas franceses, pretendía, como ya indicaba el nombre de la publicación, despertar a los ciudadanos americanos de su letargo y animarles a tomar las armas para defender sus derechos. Primero a defender su patria y su religión ante una posible invasión francesa y después a legitimar sus aspiraciones a la independencia. Además, defenderá los derechos de propiedad de la población indígena y la libertad para los esclavos.

Tras la derrota de Hidalgo en la batalla del Puente de Calderón se inició un proceso contra el periódico y sus responsables el 28 de enero de 1811. El juicio concluyó el 22 de abril con la condena a fuego de todos los ejemplares disponibles y con el encarcelamiento del administrador de la imprenta, José Trinidad Buitrón, y los impresores, José Antonio Henríquez y José María Ibarra. El castigo para Maldonado fue más sutil, se le obligó a editar en la misma imprenta El Telégrafo de Guadalajara, una publicación realista dedicada a criticar la revuelta de Hidalgo.

Mientras, el también sacerdote José María Morelos se levantaba en el Sur contra los blancos, tanto peninsulares como criollos. En 1812 se apoderó de Oaxaca y convocó un congreso en Chilpancingo donde se abolió la esclavitud y se proclamó la independencia, adoptando la forma de gobierno republicana. Pero en 1815 Morelos, que había ido perdiendo poder dentro del movimiento independentista, fue capturado y ejecutado, con lo que el levantamiento insurgente quedó extinguido.

Tanto Hidalgo como Morelos eran sacerdotes ilustrados que exigían la igualdad de derechos de mestizos e indígenas con los blancos y el reparto de las tierras. Esto suponía una gran amenaza para las élites criollas y para la Iglesia (principal propietaria de tierras en México), que inicialmente apoyaron a los peninsulares.

El segundo de los grandes periódicos insurgentes mexicanos fue el Ilustrador Nacional, del sacerdote José María Cos, que se publicó entre abril y mayo de 1812, en Cuautla, que había sido ocupada por las tropas de Morelos. La publicación se mantuvo gracias a la financiación de 'Los Guadalupes', una sociedad secreta que apoyaba la insurgencia. Tras la ocupación de la ciudad por las tropas realistas, El Ilustrador Nacional pasó a llamarse El Ilustrador Americano.

Entre julio de 1812 y enero de 1813 se publicó el Semanario Patriótico, redactado por Andrés Quintana Roo e Ignacio López Rayón. Mientras El Ilustrador se fue convirtiendo con el paso del tiempo en un boletín de partes de guerra, en el Semanario Patriótico había más reflexión política y se analizaban los derechos de las naciones.

El establecimiento de la libertad de imprenta desde octubre de 1812 produjo la aparición de otros periódicos, como el creado por Joaquín Fernández de Lizardi, El Pensador Mexicano. Esta publicación denunció los problemas de la sociedad colonial, prestando especial atención a la discriminación de los criollos en la concesión de puestos públicos y a las deficiencias del sistema educativo.

Tras la muerte de Morelos, tanto el periodismo realista como el insurgente entraron en una etapa de decadencia hasta 1821, año clave por el Plan de Iguala, que 
supuso el resurgir de los impresos y la culminación de la independencia mexicana.

En los territorios que comprendían el virreinato del Perú también encontramos publicaciones emancipadoras de gran trascendencia. En lo que hoy es Chile, tuvo especial relevancia La Aurora, publicación impulsada por la Junta de Gobierno, lide-

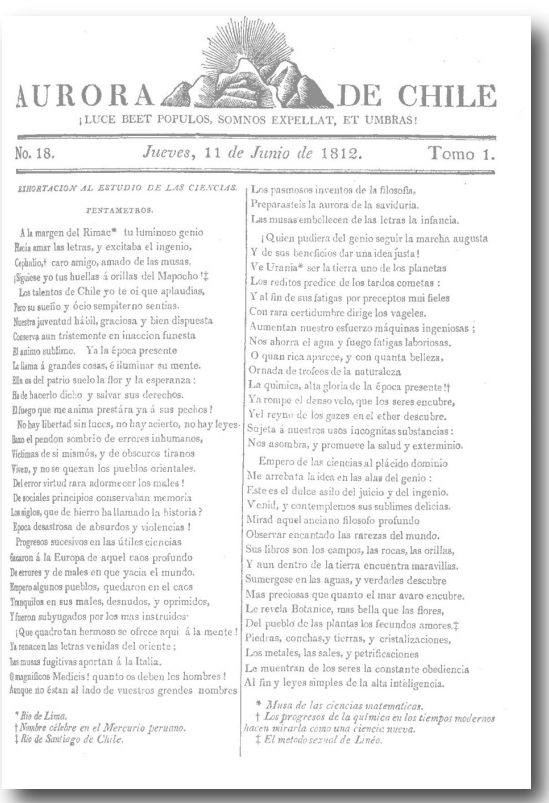
rada por Bernardo O'Higgins, que en septiembre de 1810 adoptó medidas revolucionarias, pero que inicialmente no se desligó de la metrópoli.

La Junta encargó la edición de La Aurora al sacerdote Camilo Henríquez por sus destacados "principios políticos, de religión, talento y demás virtudes naturales y civiles"13. Se publicó entre febrero de 1812 y abril de 1813 . Tenía una tirada de 500 ejemplares y estaba compuesta de dos hojas tipo folio, que daban lugar a cuatro caras, divididas con dos columnas cada una.

Como la mayoría de las publicaciones de esta época tuvo una vida breve, pero intensa, y se considera que ejerció una notable influencia en el proceso revolucionario que dio lugar a la independencia chilena.

Cuando se inició en Hispanoamérica el proceso emancipador, Perú se convirtió en un baluarte realista debido a la actuación del virrey Abascal, que supo conciliar los intereses peninsulares y criollos frente a las reivindicaciones de las clases populares y los indígenas. Tras la emancipación de Argentina y Chile, el general José San Martín desembarcó en Pisco en septiembre de 1820 al frente de su ejército libertador y tomó Lima en julio de 1821, proclamando la independencia de Perú. Sin embargo, los españoles se mantuvieron firmes en la Sierra e incluso lograron recuperar Lima. Pero a finales de 1824 fueron derrotados definitivamente por Simón Bolívar en la batalla de Ayacucho.

En el ámbito de la prensa, al amparo de una creciente libertad, aparecieron en Lima tres periódicos de signo liberal: Diario Secreto de Lima, El Peruano y El Satélite del Peruano. El Diario Secreto de Lima, obra de Fernando López Aldana, apareció de forma clandestina como manuscrito en 1811 y destacó por sus críticas contra el Gobierno. Desapareció por problemas con las autoridades. Una de sus mayores aportaciones fue, según Ríos (1994: 115), la "defensa de la soberanía popular depositada en los representantes, defendiendo por ello la igualdad de derechos de los americanos respecto a los peninsulares para decidir quiénes eran los depositarios de esa soberanía".

Entre las publicaciones impresas, encontramos El Peruano y El Satélite Peruano, ambos clausurados por el Gobierno colonial. El Peruano, fundado por el flamenco Guillermo del Río y el español Gaspar Rico, llevó a sus páginas los temas 
más candentes del momento, con especial atención a la pugna entre el virrey y los liberales. Una de las razones fundamentales esgrimidas por las autoridades coloniales para procesar a los autores de El Peruano fue que utilizaban el término patria referido al Perú y no a España. La publicación más comprometida con las ideas emancipadoras fue El Satélite Peruano (1812), que abogó por la unión de todos los americanos y también fue clausurado.

Por su parte, en el virreinato de Nueva Granada el primer movimiento independentista se remonta a 1797, liderado por Manuel Gual y José María España, pero fue abortado sin dificultades por las autoridades coloniales. En 1809 Francisco Miranda desembarcó en Coro (al noroeste de Venezuela) con una expedición libertadora que también fracasó porque no logró el apoyo de la población.

En abril de 1810 se nombró una Junta en Caracas, que en julio de 1811 proclamó la independencia absoluta. La reacción española no se hizo esperar y comenzó una larga y cruenta guerra. Después de que Miranda fuera hecho prisionero, el gran líder de la lucha por la independencia fue Simón Bolívar, que procedía de la élite criolla de Caracas y que había estudiado en Europa. Bolívar era probablemente el único líder revolucionario que podía aglutinar la lealtad de parte de los criollos y de sectores populares con intereses dispares.

Bolívar ganó la batalla de Boyacá y logró el control sobre Bogotá. Sus tropas fueron sumando victorias: en 1821 Bolívar entró en Caracas y su lugarteniente Sucre en Quito. Todas las tierras del virreinato de Nueva Granada se proclamaron independientes y quedaron integradas en la llamada Gran Colombia, bajo la presidencia del propio Bolívar.

En cuanto al papel de la prensa en todo este proceso, incluso antes de la formación de la Junta de Caracas, en marzo de 1810 apareció en Londres El Colombiano, un periódico impulsado por Francisco Miranda para ser distribuido en América. Esta publicación, que sólo duró dos meses, estaba dirigida a los americanos en general y ejerció una influencia muy directa en la clase criolla venezolana. Su propósito era informar a las provincias españolas de Ultramar de todo lo que sucedía en la corte española y en Europa.

Ya en su primer levantamiento, Miranda llevaba una imprenta, de la que salieron diversas proclamas contra las autoridades españolas. Como no pudo instalarla en tierra la vendió a un impresor inglés de la isla de Trinidad. Posteriormente este impresor, Mathew Gallagher, se instaló en Caracas con esta imprenta, con la que se publicó en primer periódico del país La Gaceta de Caracas, creado principalmente para la difusión de las noticias e ideas favorables al gobierno de la colonia, pero que a partir de abril de 1810 se convirtió en un instrumento de la Junta.

Dentro de este periodo podemos destacar también El Semanario de Caracas (18101811), publicación que inicia el periodismo independiente en Venezuela, y que contaba con sección política y otra económica. En Bogotá, el primer periódico político fue $L a$ Constitución Feliz, encomendado por la Junta Suprema al destacado periodista Manuel del Socorro Rodríguez. La Junta también encargó a José de Caldas, Joaquín Camacho y José María Gutiérrez la edición del Diario politico de Santafé de Bogotá para informar al pueblo de cuanto sucedía. Se publicó entre agosto de 1810 y febrero de 1811. 


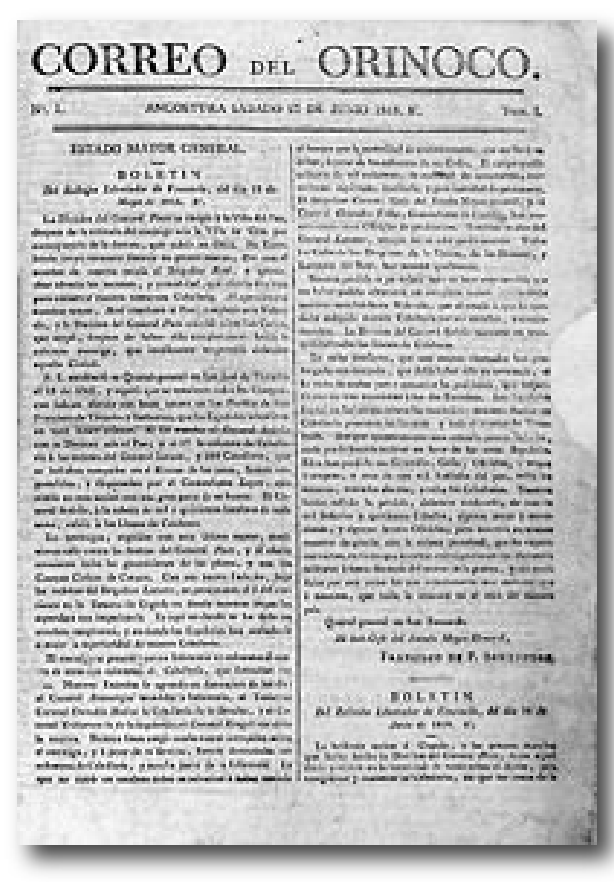

Sin embargo, la gran publicación emancipadora fue El Correo del Orinoco, del Libertador. Bolívar analizó las causas por las que había fracasado Miranda en su 'Manifiesto de Cartagena' y emprendió una enérgica campaña, tanto política como militar. Al mismo tiempo, consideró el periodismo como un instrumento de gran eficacia $\mathrm{y}$, cuando pudo disponer de una imprenta, puso en marcha El Correo del Orinoco, que apareció entre 1818 y 1822. La nueva publicación fue uno de los instrumentos más eficaces en la lucha de liberación y uno de los medios más importantes para difundir las opiniones de Bolívar. También es el medio para dirigirse a sus tropas, como muestra esta proclama de 1821: "la paz debió ser fruto del armisticio que se va a romper, pero la España ha visto con insolencia los horrorosos tormentos que padecemos por su culpa" ${ }^{14}$.

\subsection{La prensa realista}

Las autoridades españolas vieron la necesidad de contrarrestar a través de la prensa las críticas de los criollos y sus aspiraciones de autogobierno, primero, e independentistas, después. En la mayoría de las zonas este tipo de publicación llevó por título Gazeta (o Gaceta) del Gobierno.

Entre otras, se publicaron La Gazeta del Gobierno, publicada en Buenos Aires entre 1809 y 1810, la Gazeta del Gobierno de Chile (1814), la Gazeta de México, más tarde llamada Gazeta del Gobierno de México, que se publicó entre 1810 y 1821, o la Gazeta del Gobierno de Lima (1810 y 1821). La duración de estas publicaciones fue variable en función de la mayor o menor velocidad del proceso emancipador. Así, tuvieron una corta existencia en países como Argentina y Chile, y una vida más larga en otras zonas como México y Perú. Estos periódicos realistas publicaban informaciones oficiales originadas por las autoridades tanto en España como en América.

En Perú, el virrey Fernando Abascal estableció una política de compromiso y su actuación se considera clave para que la emancipación peruana se retrasara más de una década. En el ámbito de la prensa, Abascal auspició el nacimiento de La Gaceta del Gobierno de Lima, cuyo principal objetivo fue desautorizar las ideas y acciones emancipadoras. Para ello, no recurrió a los ataques directos a los patriotas sino que trató de mantener un equilibrio entre las ideas liberales moderadas y la defensa del dominio español en América. 
Además, se enfrentó a los periódicos portavoces de ideas independentistas, ya fuera clausurándolos como hizo con El Peruano y con su sucesor El Satélite Peruano, o bien facilitando la creación de publicaciones que las contrapesaran, como fue el caso del periódico oficialista El Verdadero Peruano, en cuyas páginas el virrey consiguió que colaboraran importantes miembros de la sociedad peruana.

Por su parte, La Gazeta del Gobierno de México también se esforzó en destacar los logros de la administración colonial. Era la gran publicación oficial del régimen colonial en el virreinato de Nueva España y sus páginas estaban plagadas de edictos, decretos y proclamas. Pero también tuvo espacio para ofrecer partes militares sobre el conflicto y se empleó duramente contra los revolucionarios, incluso llegó a publicar el edicto de excomunión contra los insurgentes.

También hubo otras publicaciones que defendieron los intereses de la metrópoli sin depender directamente de las autoridades coloniales, aunque muchas veces apoyadas y patrocinadas por ellas. Así, encontramos casos como El Telégrafo de Guadalajara (1811 y 1813), de la que fue redactor forzoso Francisco Severo Maldonado.

En este sentido, es especialmente llamativo el caso de México, donde encontramos diversas publicaciones impulsadas por la iniciativa privada, tanto por organizaciones como por particulares, para contrarrestar las ideas emancipadoras y, sobre todo, para criticar la revuelta liderada por Hidalgo. Entre sus autores hay peninsulares pero también criollos, numerosos eclesiásticos pero también civiles.

Así, surgieron publicaciones como El Anti-Hidalgo, El Aristarco, Diálogos entre Filopatro, Acerario y Moros, El Verdadero Ilustrador Americano, El Centinela contra los Seductores, El Amigo de la Patria, El Fénix, El Ateneo o El nuevo Aristarco.

Las dos publicaciones más destacadas son El Anti-Hidalgo y Diálogos entre Filopatro, Acerario y Moros. Aunque ambas comparten la defensa del régimen colonial y las críticas a los insurgentes, su estilo es radicalmente distinto.

El Anti-Hidalgo (1810-11) fue redactado en forma de cartas por el fraile español de la orden de los dominicos Ramón Cassaus y Torres. En esta publicación se encargó de defender los privilegios de la corona española en tierras americanas y especialmente de atacar con virulencia a Miguel Hidalgo y su familia. Así, las cartas que conformaron El Anti-Hidalgo iban firmadas por "un doctor mexicano a Miguel Hidalgo y Costilla, ex cura de Dolores, ex sacerdote de Cristo, ex cristiano, ex hombre y Generalísimo capataz de salteadores y asesinos"15.

Para Cassaus, que conocía personalmente a Hidalgo, el líder insurgente personificaba todos los males y se emplea a fondo para denigrar su figura, que cubre de insultos:

\footnotetext{
"Con que (sic) tú, execrable majadero, badulaque excelentísimo, te has creído más sabio, más atinado que cuantos han profesado el cristianismo en todos los siglos, y que cuantos racionales ha habido en todos tiempos, para imaginarte hombre capaz de abolir el quinto, sexto y séptimo mandamiento de la ley santa de Dios, y establecer una república en que las mujeres fuesen comunes costillas, los bienes de todos quedasen al arbitrio de Costilla, y la vida de los ciudadanos pendiese de la cuchilla y capricho de Costilla"16.
} 
La crítica no se limita a sus ideas y acciones, también a su aspecto físico, que relaciona con su maldad:

"Muy enemigo nuestro: Si el sistema del doctor Gall tuviera fundamentos, y dentro de poco quisiese Dios que algún discípulo suyo reconociera tu cráneo, iqué protuberancias tan irregulares, tan monstruosas, tan fatídicas encontraría en él! ¡Qué órganos de rabia y furor sin ejemplo, de brutalidad en todo y para todo!"17.

Cassaus, que llegó a ser obispo de Guatemala, criticó especialmente que Hidalgo siendo un hombre de la Iglesia se pusiera al frente de una revuelta armada. Fundamenta muchas de sus afirmaciones en citas de filósofos griegos y personajes bíblicos. Además, compara a Hidalgo con personajes para él despreciables como Calígula, Mahoma, Lutero o el propio Napoleón y da buena cuenta de las atrocidades que cometen los insurgentes que lidera:

"Saquearon los cuatrocientos bandidos las casas de ocho europeos, y los aprisionaron entre los lamentos de sus infelices esposas e hijos tiernos, dejándolos en la última miseria, tras el dolor de tan inaudito arrojo. Acreditaron su gran valor los salvajes, y el inhumano Costilla su entereza patriótica en no hacer caso de los gemidos ni volver la vista siquiera hacia las segundas víctimas de su saña. Sólo atendían a atropellar y maltratar a los maridos y padres atónitos, e iban celebrando tan señalada victoria con grandes carcajadas y alharacas, llenándolos de baldones e improperios, y para aumentar el insulto remedaban su pronunciación fuerte de las cc, y de las zz. Parecía que esta era otra señal de proscripción y matanza; como cuando la pronunciación de Scibboleth o Siboleth fue el medio de conocer a los de la tribu de Ephrain, y de que fuesen degollados en el paso del Jordán cuarenta y dos mil de ellos por los de Galaad"18.

Por su parte Diálogos entre Filopatro, Acerario y Moros fue una publicación semanal, que constó de 15 diálogos entablados por tres personajes: Filopatro, Acerario y Moros. Su autor fue el criollo José Mariano Beristaín y Souza, también colaborador de otras publicaciones realistas como El Amigo de la Patria y El Verdadero Ilustrador Americano.

Beristaín, que desempeñó importantes cargos en la administración colonial, destaca los beneficios que el Virreinato de Nueva España había recibido de la metrópoli y afirma que la insurrección era injusta. Para convencer al lector de sus ideas utiliza un método muy didáctico en el que sus tres personajes debaten sobre todas estas cuestiones. Filopatro, el amigo de la patria, es el personaje principal, Acerario es un español que pregunta por las razones de la guerra y Moros es un criollo que cuestiona los motivos del levantamiento. En sus explicaciones, el autor sostiene que el movimiento insurgente se debe a la rivalidad entre 'gachupines y criollos' y aboga por eliminar estos términos y sustituirlos por otros como 'españoles de acá y de allá', 'español americano y español europeo' o 'español nuevo y español viejo'.

Aunque también es muy crítico con Hidalgo y sus reivindicaciones su tono no tiene nada que ver con el de El Anti-Hidalgo. Critica sus intentos de reforma porque privaría a los criollos y a los peninsulares de lo que legítimamente les corresponde 
por su trabajo o por justa adquisición y le acusa de estar confabulado con los franceses para repartirse el territorio americano:

"Filopatro: ¿No están demostrando aún a los lerdos que es hijo de la Francia y de Napoleón el proyecto de Hidalgo, y que éste ha sido la partera o comadrón de parto tan infernal? [...]

Acerario: Se les pintará a los indios con cuanto horror se pueda la injusticia y crueldades con que los españoles conquistaron... Se les dirá que tienen usurpada su tierra... Se les ofrecerá quitarla del poder de los usurpadores, y repartírsela, y librarlos del yugo que los oprime... ¿Qué le parece a Ud. señor Moros? A Dios hacienda que le dejó a Vd. su tía, adiós trabajo del padre Montañés y del abuelo Catalán... ¿Cuándo volverá Ud. a ver el dinerito que ahora le dan los arrendadores? Moros: Pues en eso estaba yo pensando; y ese es mi miedo, y digo: los ranchos que tienen en Tierra Caliente, y en Tierradentro, y por todas partes los mulatos, y otras castas, también irán a los indios, según el plan del señor Napoleón”19.

\section{Conclusiones}

La principal conclusión de este trabajo es que, pese a que durante los procesos emancipadores de América Latina el número de lectores era muy pequeño y se limitaba a sectores de las élites -criollas y peninsulares- y las imprentas eran escasas y estaban muy controladas por las autoridades, tanto los realistas como los insurgentes trataron de utilizar todo tipo de escritos (fundamentalmente bandos, edictos, gacetas y panfletos) para dar a conocer sus ideas, criticar al rival, y convencer y educar a los ciudadanos.

Esta función formativa de la prensa se había iniciado ya en el último tercio del siglo XVIII con las publicaciones ilustradas, que sentaron las bases para lo que luego fue la prensa emancipadora.

La palabra escrita se convierte así en un arma más de guerra. Las publicaciones patriotas y realistas defienden objetivos totalmente contrapuestos pero, como hemos podido comprobar en los textos analizados, suelen basar sus argumentos en ideas muy semejantes. Por una parte destaca la idea de defensa de la patria y los dos bandos se consideran los 'verdaderos patriotas', también van a coincidir en la defensa de la religión católica y, al menos inicialmente, en la de la figura del rey Fernando. Por otra parte, ambos bandos se muestran contrarios a la invasión francesa.

\section{Referencias bibliográficas}

ALVAREZ, J. T. y MARTÍNEZ, A (1992). Historia de la Prensa Hispanoamericana. Madrid: Mapfre.

ARGUDÍN, Y. (1987). Historia del periodismo en México. México: Panorama.

BERNEDO, P. (2004). "Nacimiento y desarrollo de la prensa periódica nacional en

América Latina" en BARRERA, C. (Coord.) (2004). Historia del Periodismo

Universal. Barcelona: Ariel. 
CHECA, A. (1993). Historia de la Prensa Iberoamericana. Sevilla: Alfar.

DEL PALACIO, C. (Comp.) (2000). Historia de la Prensa en Iberoamérica. Guadalajara: Altexto.

GARGUREVICH, J. (1991). Historia de la Prensa peruana 1594-1990. Lima: La Voz.

GUERRA, F. X. (2002). "El escrito de la Revolución y la revolución del escrito", en TERÁN, M y SERRANO ORTEGA, J.A (2002). Las guerras de independencia en la América española, Michoacán: El Colegio de Michoacán.

HALPERIN DONGUI,T. (1993). Historia Contemporánea de América Latina. Madrid: Alianza.

HERNÁNDEZ DÁVALOS, J. E. (Ed. 2007). Historia de la Guerra de Independencia de México. México: Universidad Nacional Autónoma de México.

MARTÍNEZ, P.F. (2009). "El pensamiento agrario ilustrado en el Río de la Plata: un estudio del Semanario de Agricultura, Industria y Comercio (1802-1807)" en Mundo Agrario, v.9, n.18, La Plata.

Novísima recopilación de las Leyes de España. Dividida en doce libros. Libro VIII, Títulos XV, XVI, XVII y XVIII. Accesible en la web http://biblioteca.universia.net/ficha.do?id=38581909

RÍOS, E. (1994). "El periodismo en Iberoamérica” en PIZARROSO, A. (Coor.) (1994). Historia de la Prensa. Madrid: Centro de Estudios Ramón Areces.

\section{Notas}

1 La colección del Diario Literario de México se encuentra digitalizada en la Universidad de Michigan http://quod.lib.umich.edu/cgi/t/text/text-idx?c= genpub;idno=1983280.0001.001, Última consulta 20-10-2010

2 Todos los ejemplares de El Mercurio Volante están disponibles en la web www.filosofia.org/ave/001/a267.htm Última consulta 25-10-2010.

3 El Telégrafo Mercantil se encuentra digitalizado en la Hathi Trust Digital Library, en el siguiente enlace http://hdl.handle.net/2027/njp.32101025281500, Última consulta 3-5-2011

4 Novísima recopilación de las Leyes de España. Dividida en doce libros. Libro VIII, Títulos XV, XVI, XVII y XVIII. Accesible en la web http://biblioteca.universia.net/ficha.do?id=38581909, Libro VIII, p. 528.

$5 \quad$ Ibid, p.82 у p.121.

6 DE LA TORRE VILLAR, Ernesto, GARCÍA LAGUARDIA, José Mario (1976). Desarrollo histórico del constitucionalismo hispanoamericano. Vol. 11, serie B. México: Instituto de Investigaciones Jurídicas de la UNAM. Texto en la web, parte 3, p.10 en www.bibliojurídica.org/libros/2/809/3.pdf, Última consulta 20-10-2010

7 Recogido en www.educarchile.org, Última consulta 28-10-2010.

8 Recogido en http://www.manuelbelgrano.gov.ar/belgrano_y_periodismo.htm, Última consulta 23-10-2010. 
9 El Despertador Americano, $\mathrm{n}^{\circ}$ 1, 20 diciembre 1810, página 1. Todos los ejemplares están recogidos en la Biblioteca Virtual Antorcha http://www.antorcha.net/ index/hemeroteca/despertador/despertador.html. Última consulta 24-10-2010.

10 Ibid, p. 3.

11 El Despertador Americano, $\mathrm{n}^{\mathrm{o}}$ 2, 27 diciembre 1810, p. 7, Última consulta 23-102010

12 El Despertador Americano, $\mathrm{n}^{\circ}$ 3, 29 diciembre $1810 \mathrm{en} \mathrm{http://www.bicentenarios.es,}$ Última consulta 25-10-2010.

13 Decreto de 1812 por el que se encargaba la edición a Henríquez. Todos los ejemplares de esta publicación e información sobre la misma en www.auroradechile.cl, Ultima consulta 26-10-2010

14 El Correo del Orinoco, 19 de mayo de 1821. Colección de la autora.

15 Todas las cartas de El Anti-Hidalgo disponibles en http://www.biblioteca.tv/artman2 /publish/1810_115/El_Anti-Hidalgo_Cartas_de_un_doctor_mexicano_al_se_or Hidalgo_printer.shtml. Última consulta 28-10-2010.

16 El Anti-Hidalgo, carta cinco.

17 El Anti-Hidalgo, carta dos.

18 El Anti-Hidalgo, carta cuarta.

19 Cfr. Hernández Dávalos (2007: 713-714).

\section{La autora}

Marta González San Ruperto es Licenciada y Doctora en Ciencias de la Información por la UCM, y Licenciada en Ciencias Políticas por la UNED. Ha compatibilizado su trabajo como periodista en diversos medios de comunicación y empresas con las labores docentes en la Universidad Carlos III y en la Universidad Complutense de Madrid. Entre sus líneas de investigación destaca el estudio de la información y propaganda de guerra y el periodismo en Europa e Iberoamérica. 